\section{BASCD launches rebrand in Oxford}

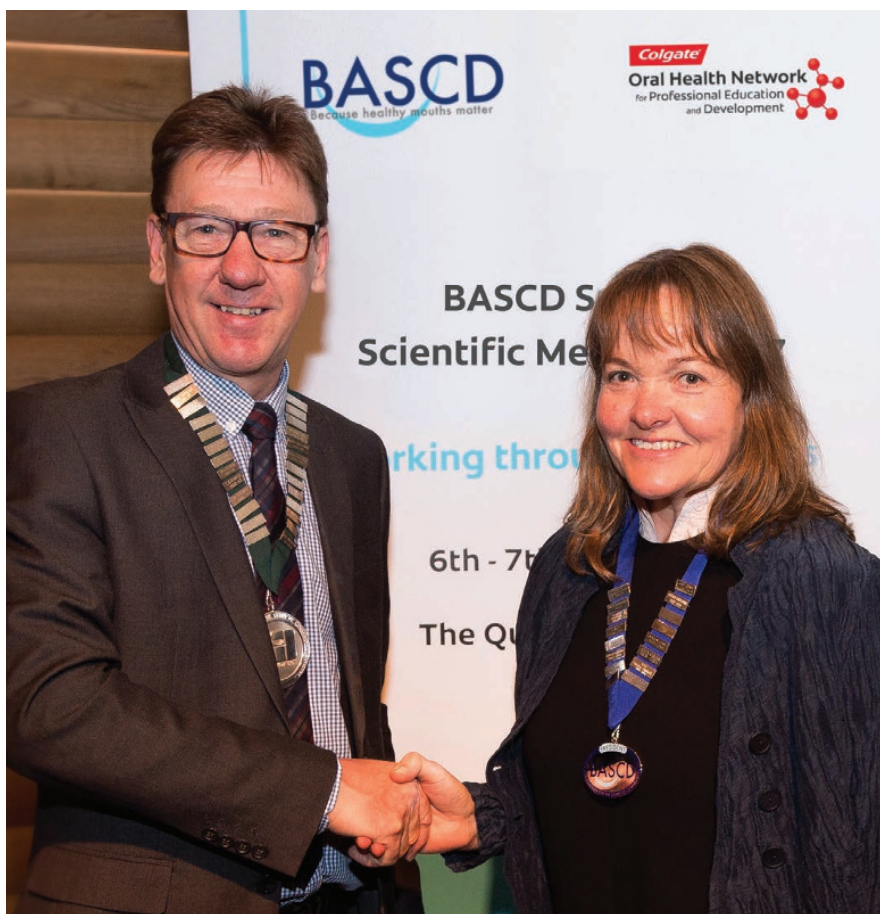

The Presidential Spring Scientific meeting of the British Association for the Study of Community Dentistry (BASCD) was held in Queen's College, Oxford University on 6-7 April 2017.

Delegates witnessed the launch of a contemporary, fresh look to the BASCD logo, incorporating the society's new strapline 'Because healthy mouths matter' which describes the essence of the BASCD philosophy. The new branding extends to a new Twitter feed and the redesign of the associated journal website, Community Dental Health. Eric Rooney, Deputy Chief Dental for England and outgoing BASCD President, presented a new Presidential medal incorporating the new logo to new President Professor Rebecca Harris (pictured).

The Presidential conference theme of 'Working through networks' included many high profile speakers such as Sir Muir Gray (pioneer of NHS screening programmes and creator of the National Library for Health), Deputy Chief Dental Officer of England Janet Clarke, Chief Dental Officer of Wales Colette Bridgman, and Chief Dental Officer of Scotland Margie Taylor. Insights into influencing high level health strategy were also provided by John Gisborne (Managing Director of the global health communications firm FleishmanHillard Fisburn) and Professor Susan Jebb (the UK Government's advisor on obesity).

Professor Harris said: 'The new medal feels like it marks the beginning of a new BASCD era. It was so exciting to see so many young people really enjoying the conference, making new friends and taking their place as the next generation of dental public health practitioners and academics. The beautiful setting of an old Oxford college and spectacularly sunny weather made sure we will all remember it for a long time to come'.

The Autumn BASCD Scientific conference will be in London on Thursday 16 November 2017 and will be focused on 'Working with communities'.

\section{Dates for your diary}

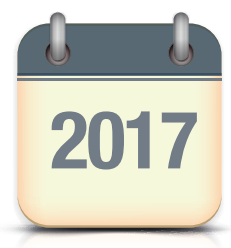

\section{National Smile Month}

Date: 15 May - 15 June 2017

Details: The UK's largest and longest running oral health campaign, organised by the Oral Health Foundation. It aims to increase awareness of important oral health issues and make a significant difference to the well-being of millions of people. Supported by thousands of individuals and organisations, National Smile Month promotes three key messages at the heart of good oral health: brush your teeth last thing at night and at least one other time during the day with a fluoride toothpaste; cut down on how often you eat sugary foods and drinks; and visit the dentist regularly, as often as they recommend.

If you have not done so yet, visit www.smilemonth.org/register to support and take part in National Smile Month.

\section{BAOMS annual conference}

Date and location: 28-30 June 2017, ICC Birmingham Details: The key debate at this year's conference will be around the impact and future of the dual degree, whether to continue and what the alternatives could be.

The preliminary programme can be found at https://www. baoms.org.uk/_userfiles/pages/files/asm_2017_birmingham/ birmingham_prelim_2017_011.pdf.

\section{Nutrition, Oral Health \& Performance Symposium}

Date and location: Friday 28 July 2017, Torrington Place,

London, WC1E 7JE

Details: A ground breaking, one-day symposium in sport and exercise medicine and oral health. Expert speakers will explore:

- State-of-the-art developments and future of sport nutrition (Dr Kevin Currell \& Professor Ron Maughan)

- Sport nutrition and health (Dr Dan Kings)

- Eating disorders \& RED-S in athletes (Dr Anna Katarina Melin)

- Oral health \& sport performance (Professor Ian Needleman, Dr Paul Ashley \& Dr Julie Gallagher).

The symposium will be highly relevant to sport and exercise medicine clinicians and scientists, nutritionists, performance directors, dental care professionals and researchers. Full details available at www.ucl.ac.uk/cohp.

\section{British Endodontic Society Regional Meeting}

Date and location: 17-18 November 2017, Edinburgh

Theme: Endodontic infections and systemic health

Further details will become available at http://www.britishendodonticsociety.org.uk/. 